\title{
$\operatorname{arCOS} D E S I G N$
}

\section{Aspectos que influenciam a seleção de materiais no processo de design}

Eliana Paula Calegari (UFRGS, Brasil)

elianapaulac@gmail.com

Escola de Engenharia - Programa de Pós-Graduação em Design

Av. Osvaldo Aranha, 99, Porto Alegre - RS, CEP: 90040-060

Branca Freitas de Oliveira (UFRGS, Brasil)

branca@ufrgs.br 


\title{
Aspectos que influenciam a seleção de materiais no processo de design
}

Resumo: Os materiais possuem características que os tornam únicos, assim, é preciso analisá-las para selecionar o material mais adequado para determinado produto. Este trabalho objetiva verificar os aspectos dos materiais que influenciam a seleção dos materiais sob o ponto de vista de designers de produto. Através de entrevistas e análise de conteúdo, o estudo revelou que nas etapas iniciais do processo de design, os designers direcionam a seleção de materiais para os aspectos intangíveis e nas etapas posteriores para os tangíveis.

Palavras-chave: design de produto, processo de design, seleção de materiais.

\section{Aspects that influence the selection of materials in the design process}

\begin{abstract}
The materials have characteristics that make it unique, so we must analyze them to select the most suitable material for a particular product. This work aims to verify aspects of the materials that influence the selection of materials from the point of view of product designers. Through interviews and content analysis, the study revealed that in the early stages of the design process, designers guide the selection of materials for intangibles and subsequent steps for tangible.
\end{abstract}

Key words: product design, process design, materials selection. 


\section{Introdução}

Os materiais tiveram grande relevância para o desenvolvimento da sociedade, pois por meio deles o homem materializou seus artefatos que o ajudaram na sua sobrevivência. Manzini (1989) observa que no primeiro milhão de anos de sua existência o homem utilizou essencialmente a madeira, pedra, ossos, chifres e couro para construir ferramentas e objetos. No decorrer do tempo surgiram diversos materiais, entre eles os metais, e ao longo de 9.000 anos da história, foram os materiais mais empregados pela humanidade. Com a Revolução Industrial, ocorreram profundas transformações em âmbito cultural, social e econômico, o que tornou acelerada a multiplicidade de materiais disponíveis para a produção de produtos. Nesta época, houve o impulso do design devido à necessidade de criação de produtos e o planejamento da produção com base no desenvolvimento em série.

Os materiais desempenham papel essencial no processo de concepção dos produtos, pois concretizam as ideias, os conceitos e desenhos criados pelos designers. A relação entre materiais e design fica evidente nas compreensões de alguns autores da área, como nas constatações de Ashby e Johnson (2010): "materiais são a matéria de que é feito o design de produto" (p. 55), e "interagimos com materiais por intermédio de produtos" (p. 81). Gomes (2006, p. 151) também trata desta relação, quando diz que "materiais são componentes físicos que constituem um produto". Em consonância, Ferrante e Walter (2010) argumentam que a ponte de ligação entre a ideia e a produção é o material, que deve ser selecionado e processado até a reprodução física da ideia na forma de produto, levando em consideração as mais diversas condições de uso que o material precisa prever e atender. Para Beylerian e Dent (2007, p. 17) "materiais podem transformar o design, e o design, portanto, tem a força para transformar nossas vidas".

Nesta ótica, os autores supracitados têm visões parecidas no que toca a relação dos materiais com o design, porém diferenciam-se na complexidade. Assim, a relação compreendida por eles vai desde a concretização de uma ideia até a possível transformação da vida das pessoas, ou seja, a ideia de materializar um produto de design parece estar associada à melhoria da qualidade de vida dos seres humanos. Outro importante apontamento sobre a relação dos materiais com o design é a afirmação de Beylerian e Dent (2007) de que os materiais podem ser considerados como uma das fontes mais ricas de inovação, pois segundo eles, podem promover o design inovador. Esta constatação, em nível distinto, também está presente na terceira edição do Manual de Oslo, quando aborda que melhoramentos significativos em produtos podem ocorrer por meio de mudanças em materiais empregados, que aprimoram seu desempenho. 
Os materiais com os quais os produtos são produzidos são portadores de significados perceptíveis aos usuários, assim, podem influenciar as suas escolhas e preferências. Para Ashby e Johnson (2010), a materialidade cria a personalidade de um produto, pois um material possui atributos percebidos ou associações que os adquire quando usado em um produto. $\mathrm{O}$ designer pode incorporar diferentes significados em um produto, dependendo do papel que ele desejar que o produto desempenhe. Como exemplo, no caso da madeira, os autores argumentam que é um material natural cujas fibras proporcionam uma textura de superfície própria deste material, ela é tátil, percebida como mais quente em comparação com outros materiais, e aparentemente mais macia, possui cheiros característicos e desperta associações com o artesanato. Assim, a madeira é um material bem conhecido, possui características que podem estar associadas a significados atribuídos pelos usuários. Neste sentido, os autores observam que estas características não são apenas estéticas, mas sim, traços que definem uma personalidade, que pode ser revelada pelo designer.

Neste sentido, os materiais possuem significados que são percebidos tanto por designers como por usuários. Porém, o tipo de material e a forma como o designer irá empregar o material em um produto, implicará na sua personalidade, e por consequência, na percepção dos usuários. Tanto os significados dos materiais, quanto a personalidade dos produtos, dependem do contexto cultural em que são utilizados. Assim, o emprego de materiais no design de produto precisa ser fundamentado também pela cultura, para que os designers consigam atender as necessidades do público-alvo do produto.

Desse modo, a forma do produto é influenciada por diversos fatores culturais, como a moda, o prazer, o luxo, novidade, humor e outros, e sobretudo pelos materiais e processos (ASHBY e JOHNSON, 2010). Assim, os materiais exercem influências sobre a configuração dos produtos, já que a forma de determinado produto é dependente do material e de suas características. O autor enfatiza que o bom design é aquele que leva em consideração o uso mais eficiente dos materiais, ou seja, de suas propriedades e da maneira como podem ser conformados. Neste ponto, o designer pode explorar as propriedades favoráveis de determinado material e corrigir as suas deficiências.

Neste contexto, o objetivo deste trabalho é identificar os aspectos dos materiais que influenciam na seleção de materiais durante o processo de design. Para isso foram realizadas entrevistas com designers de produto e para a análise dos dados foi utilizada a análise de conteúdo. Dessa forma, foram elencados os aspectos dos materiais que os designers levam em consideração na escolha dos materiais e a relação destes com o processo de design. 


\section{Seleção de materiais e design}

A cada dia a ciência e a tecnologia estão avançando e por consequência surgem diversos novos materiais. Atualmente, são ilimitadas as possibilidades de materiais e a combinação entre eles para a obtenção de diferentes propriedades e desempenhos. De acordo com Manzini (1989), no início do século xx, eram necessários menos de 100 materiais diferentes para a fabricação de um automóvel, hoje o processo exige mais de 4.000 materiais. Devido a grande quantidade de materiais disponíveis para serem empregados em um produto, é necessário selecionar o mais adequado. Segundo Dias (2009), a seleção de materiais ocorre em distintas situações em uma empresa:

- Na criação de um produto, em que não há limitações sobre o material;

- Na criação de um novo produto para uma empresa que já tenha um processo produtivo que pré-determina certos materiais;

- Modificações ou redesign de um produto visando um melhor desempenho técnico;

- Alteração de materiais para a redução de custos;

- Trabalhar sempre com materiais disponíveis e com custos reduzidos, além de outras situações.

Para o designer, a situação em que não há limitações na escolha dos materiais é a ideal, ou seja, é mais motivador para ele trabalhar com a liberdade para selecionar o material mais apropriado. Porém, na maioria das situações de seleção de materiais este profissional trabalha atrelado a limitações que dirigem para o uso de determinados materiais e processos, como é o caso da maioria das situações citadas anteriormente.

Neste contexto, segundo Kindlein e Busko (2006), independente da situação e do setor ou porte da empresa, é desejável a participação de uma equipe multidisciplinar para proceder a seleção do material no contexto do processo de desenvolvimento do produto. Conforme Dias (2009), tradicionalmente, a seleção de materiais é realizada pela equipe de desenvolvimento da empresa, e em alguns casos ocorre o auxílio de profissionais especializados. Isso ocorre, pelo fato de que a seleção de materiais envolve diversos conhecimentos, desde propriedades técnicas até aspectos estéticos, simbólicos e práticos dos materiais. Desse modo são necessárias informações de áreas como a engenharia e o design para a escolha efetiva dos materiais.

De acordo com Ashby e Johnson (2010), o ato de seleção de materiais envolve a conversão de requisitos de projeto, em um conjunto de resultados em forma de uma lista de materiais e processos viáveis. Desse modo, os critérios 
definidos para determinado projeto dominam o processo de seleção de materiais (KARANA et al., 2007). Assim, o ponto de partida da seleção de materiais são as diretrizes básicas do projeto.

A seleção de materiais ocorre na medida em que vão sendo avançadas as etapas do processo de design, assim, os materiais estão presentes no percurso do Processo de Desenvolvimento de Produto (PDP). Conforme Ashby e Johnson (2010), as principais etapas do PDP possuem correspondência com a seleção de materiais, como pode ser visualizado na figura 1 .

\section{Necessidade/ideia}

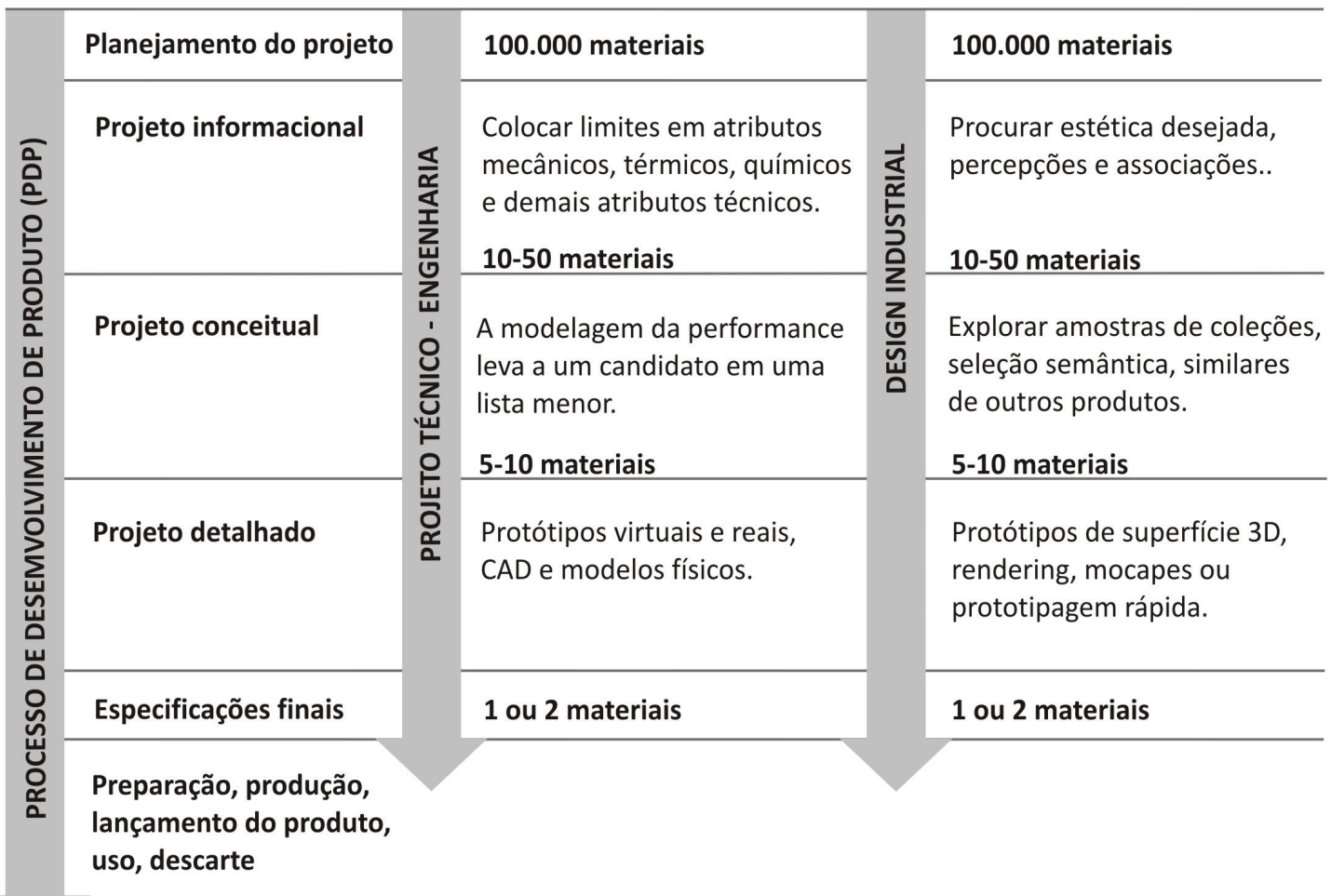

Figura 1. Seleção de materiais no Processo de Desenvolvimento de Produtos.

Fonte: Adaptado de Ashby e Johnson (2010).

A partir do exposto, os autores ressaltam que o designer necessita de informações sobre materiais em cada etapa do projeto. Em termos do nível de precisão, a informação necessária nos primeiros estágios é muito distinta da que será necessária mais adiante. Assim, na primeira etapa de desenvolvimento, as informações necessárias são para um subconjunto de materiais, na próxima fase é preciso um nível mais alto de precisão e detalhe e no estágio final do projeto a exigência é para uma condição de exatidão e detalhe ainda maior. Desse modo, o grau de informações sobre materiais aumenta à medida que o projeto avança. 
Dias (2009) destaca que é necessário que a seleção de materiais seja considerada durante todo o processo de desenvolvimento de produto, pois, há uma forte relação entre o custo para modificar um projeto e a etapa em que a falha ocorre. Desse modo, os gastos com alterações no início do projeto são menores do que em etapas posteriores, como no detalhamento do projeto que envolve ferramentaria e lançamento do produto.

\section{0 perfil dos materiais}

Os materiais diferenciam-se uns dos outros por possuírem características particulares, que segundo Dias (2009) é uma espécie de perfil genético, ou seja, o DNA do material. Os materiais são classificados em: família, classe e membro, sendo que esta classificação é baseada na natureza dos átomos e a ligação entre eles (CALLISTER, 2006). Cada membro de materiais possui atributos que podem ser definidos como características tangíveis e intangíveis. Aqueles, constituem o perfil objetivo ou técnico que visam quantificar o comportamento quanto aos atributos físicos, mecânicos, térmicos e outros, assim, podem ser medidos e possuem valores exatos. Já os atributos intangíveis, são características que definem o perfil subjetivo dos materiais, como, as questões relacionadas com a estética e o simbólico percebido pelas pessoas, estes atributos precisam ser compreendidos em termos socioculturais na medida em que são construídos socialmente. É importante frisar, que os atributos variam de acordo com o tipo de material (DIAs, 2009).

Neste contexto, o perfil objetivo dos materiais é composto por informações geralmente numéricas, como valores de força, módulos, dureza, ductilidade, condutividade térmica, coeficiente de expansão, peso, preço, e outros. Essas informações são necessárias para o cálculo de cargas seguras, temperatura, fluxo de calor, ciclo de vida, que asseguram os requisitos funcionais, técnicos, ambientais e econômicos estabelecidos para o projeto (ASHBY e JOHNSON, 2010). Dessa forma, os autores elaboraram alguns atributos tangíveis que compõe o perfil objetivo dos materiais:

- Gerais: preço e densidade;

- Técnicos: comportamento físico, mecânico, térmico, elétrico e processo de fabricação;

- Ambientais: legalidade, disponibilidade, uso de recursos naturais, impactos da extração de recursos, conteúdo energético, conteúdo de material reaproveitado, uso de materiais locais, uso de materiais renováveis, resíduos e emissões, potencial de reaproveitamento, qualidade do ambiente de uso dos materiais; 
- Sociais: aspectos sociais decorrentes da extração de recursos e manufatura;

- Econômicos: custos de ciclo de vida dos materiais aplicados ao produto.

Além do perfil objetivo, os materiais possuem o perfil subjetivo, que conforme Dias (2009) é definido por características intangíveis, ou seja, por significados atribuídos e emoções evocadas que não podem ser exclusivamente identificadas por valores numéricos ou quantificadas. Sendo assim, a autora organizou as informações sobre as características intangíveis em quatro grupos de atributos subjetivos:

- Estéticos: estes atributos estão relacionados com a impressão estética que são sentidas sobre um objeto por meio dos sentidos, assim, forma, figura, sensações de tato, textura dos materiais, peso, transparência, brilho, cheiro, são atributos que são traduzidos pela dimensão estética;

- Práticos: são os atributos que relacionam-se diretamente com o uso, manuseio e experiência dos usuários com os objetos, desse modo, os atributos como usabilidade, ergonomia, conforto, segurança, limpeza e higiene, saúde, qualidade, desempenho, confiabilidade, resistência, fazem parte da dimensão prática e de uso dos materiais;

- Simbólicos: estes atributos estão relacionados com aspectos psíquicos e sociais, que são sujeitos a variações culturais e sociais, a experiência do indivíduo, as diferenças individuais e dos valores de cada um e da coletividade, com isso, a dimensão simbólica dos materiais pode ser revelada em atributos como, identidade, memória, cultura, natural e artificial, autêntico e imitações, artesanal e industrial, valores, estilos de design e associações;

- Outras influências que afetam a percepção dos materiais: estes atributos são relativos às características dos usuários como idade, gênero, experiência, instrução, estilo de vida, além de influências de comportamento como tendências, estilos de design, bem como influências culturais.

Sendo assim, o perfil dos materiais é constituído pelo perfil objetivo e subjetivo, conforme pode ser visualizado no esquema da figura 2. Desse modo, o perfil objetivo é composto por atributos que são tangíveis ou mensuráveis, já os atributos do perfil subjetivo são intangíveis e não podem ser quantificados. O esquema mostra de forma simplificada os atributos técnicos, estéticos, práticos, simbólicos e outras influências que fazem parte deste perfil. 


\begin{tabular}{|c|c|c|}
\hline Perfil objetivo & \multicolumn{2}{|c|}{ Perfil subjetivo } \\
\hline Atributos técnicos & Atributos estéticos & Atributos simbólicos \\
\hline Gerais & Forma & Cultura e tradição \\
\hline Densidade & Cor & Memória \\
\hline Preço & Transparência & Envelhecimento \\
\hline & Brilho & Natural e artificial \\
\hline Técnicos & Tátil & Autêntico e imitação \\
\hline Atributos físicos & Textura & Artesanal e industrial \\
\hline Atributos mecânicos & Som & Inovação \\
\hline Atributos térmicos & Cheiro & Identidade \\
\hline Atributos elétricos & Sabor & Valor de marca \\
\hline Atributos de processo & Temperatura & $\begin{array}{l}\text { Valor da imagem } \\
\text { Preço }\end{array}$ \\
\hline Ambientais & Atributos práticos & Valor social \\
\hline Legalidade & Identificação & Valor sentimental \\
\hline Disponibilidade & Usabilidade & Fetiche \\
\hline Uso de recursos naturais & Ergonomia & Metáfora \\
\hline Impactos da extração de recursos & Contexto de uso & Associação \\
\hline Conteúdo energético & Conforto & Padrões \\
\hline Uso de materiais locais & Segurança e proteção & Estilo de design \\
\hline Uso de materiais renováveis & Limpeza e higiene & Personalidade \\
\hline Resíduos e emissões industriais & Saúde e salubridade & \\
\hline Conteúdo de material reaproveitado & Sustentabilidade & Outras influências \\
\hline Potencial de reaproveitamento & Qualidade & Pefil do usuário \\
\hline Qualidade do ambiente de uso & Desempenho & Gênero \\
\hline 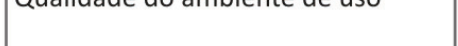 & Confiabilidade & Idade \\
\hline Sociais & Resistência & Profissão \\
\hline Extracão de recursos e & Eficiência energética & Experiência \\
\hline manufatura & Durabilidade & Estilo de vida \\
\hline Econômico & & Influência de comportamento \\
\hline Custos de ciclo de vida & & Tendências \\
\hline custos de cicio de viad & & Consumo virtual \\
\hline & & Consumo consciente e ético \\
\hline & & $\begin{array}{l}\text { Beneticios } \\
\text {-.. }\end{array}$ \\
\hline
\end{tabular}

Figura 2. Perfil do material: possíveis atributos objetivos e subjetivos.

Fonte: Adaptado de Dias (2009).

Em última análise, de acordo com a autora, o perfil dos materiais pode orientar a equipe de projeto na identificação dos atributos relevantes para determinado projeto. Assim, ele pode ser considerado genérico, pois possui atributos que muitas vezes não são aplicados para determinados materiais-produtos. Dessa maneira, não pode ser considerado com uma lista fechada, mas pelo contrário, pode ser ampliado ou reduzido dependendo da necessidade de cada projeto. 


\section{Metodologia}

No presente estudo foram realizadas entrevistas com designers de produto, a fim de verificar as características dos materiais que os designers consideram na seleção de materiais durante o processo de design. Para isso, foram entrevistados 15 designers com graduação na habilitação projeto de produto, destes, 3 mestres em design e 11 mestrandos em design.

Os dados empíricos foram coletados em campo através de entrevistas com roteiro semi estruturado, como pode ser visualizado no quadro 1. As entrevistas foram captadas por meio de gravador digital de voz, transcritas de forma integral, e posteriormente tratadas com a técnica de análise de conteúdo do tipo categorial, seguindo a abordagem de Bardin (2011), em que foi realizada uma operação de "classificação de elementos constitutivos de um conjunto por diferenciação e, em seguida, por reagrupamento segundo o gênero (analogia), com os critérios previamente definidos" (p. 46), o que permitiu a condensação e a representação simplificada dos dados brutos encontrados. Para o tratamento dos dados foi utilizado o programa RQDA ( $R$ Package for Qualitative Data Analysis) afim de auxiliar o processo de análise dos mesmos.

Quadro 1. Roteiro semi estruturado para a realização das entrevistas.

1. Baseado em suas experiências projetuais, em que etapa do processo de design você normalmente pensa sobre o possível (is) material (is) que irá empregar no produto? Por que?

2. Quais são as informações sobre materiais que você considera necessárias para a seleção de materiais?

3. Você leva em consideração fatores estéticos na seleção de materiais? Qual (is)?

4. Você leva em consideração fatores simbólicos na seleção de materiais? Qual (is)?

5. Você leva em consideração fatores práticos na seleção de materiais? Qual (is)?

7. Você leva em consideração percepções sensoriais na seleção de materiais? Qual (is)?

8. Você leva em consideração fatores técnicos na seleção dos materiais? Qual (is)

Após a transcrição das entrevistas, foi realizada a leitura de todas elas para iniciar o processo de classificação dos dados em subcategorias. As subcategorias são palavras ou pequenos grupos de palavras que são definidas a partir da frequência em que aparecem nos discursos dos entrevistados, além da maior representatividade (BARDIN, 2011). Após a definição das subcategorias, estas foram agrupadas em macro categorias. Este agrupamento foi realizado por meio de critérios representativos, ou seja, por temáticas que envolvem as subcategorias. Assim, a partir das subcategorias encontradas, estas foram agrupadas em três macro categorias: as propriedades técnicas, as propriedades sensoriais e as características intangíveis. Na análise dos dados, estas macro categorias foram teorizadas por Reis (2003), Beylerian e Dent (2007), Karana et al. (2007), Dias (2009), Ashby e Johnson (2010). 


\section{Resultados e discussão}

Selecionar e combinar materiais para um produto manufaturado é crucial para o design. Este processo de seleção de materiais envolve diversos fatores, que segundo os discursos dos designers são: as propriedades técnicas, as sensoriais e as características intangíveis, conforme mostra o gráfico da figura 3. Tal constatação vai ao encontro da visão de Dias (2009), que destaca que os materiais diferenciam-se uns dos outros por possuírem características particulares, que podem ser definidos como atributos tangíveis e intangíveis. Aqueles constituem o perfil objetivo ou técnico que visam quantificar o comportamento quanto aos atributos físicos, mecânicos, térmicos e outros, assim, podem ser medidos e possuem valores exatos. Já os atributos intangíveis, são características que definem o perfil subjetivo dos materiais, como, as propriedades sensoriais, que envolvem a percepção dos usuários através dos cinco sentidos, o tato, a visão, a audição, o paladar e o olfato. Além disso, fazem parte dos atributos intangíveis as questões relacionadas com a estética e o simbólico percebido pelas pessoas, estes atributos devem ser compreendidos em termos socioculturais na medida em que são construídos socialmente (DIAS, 2009).

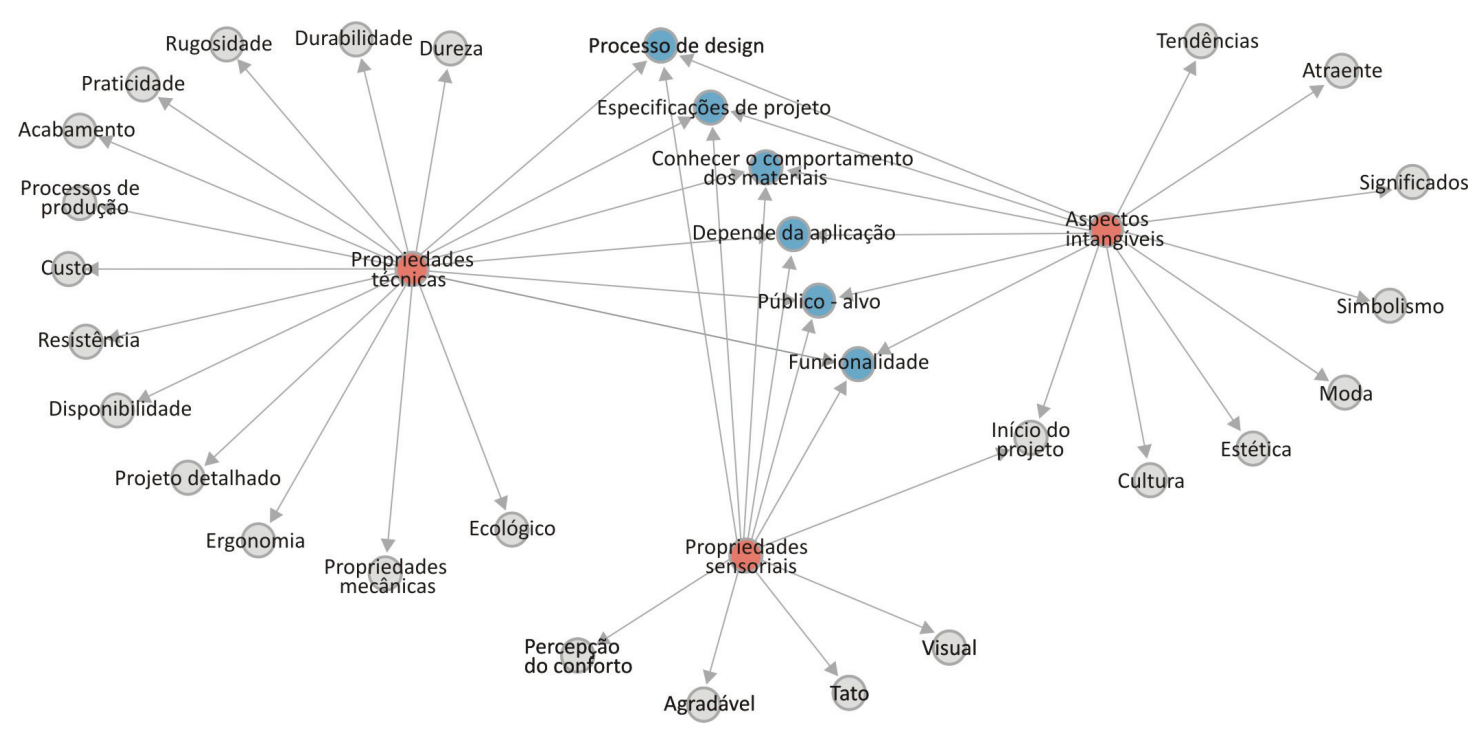

Figura 3. Rede de atributos dos aspectos que influenciam a seleção de materiais revelados pelos designers de produto. Fonte: Imagem gerada através do software RQDA (2002).

De acordo com os entrevistados, as propriedades técnicas são relevantes para a seleção de materiais, pois de forma geral, estabelecem a capacidade de um material ser adequado para determinada aplicação. Dessa maneira, eles destacam as seguintes: propriedades mecânicas, resistência, dureza, 
acabamento, durabilidade, disponibilidade, custo, material ecológico, ergonomia, processos de fabricação.

Essas propriedades, conforme os designers são importantes para o desenvolvimento de produtos, no entanto, no campo de trabalho do designer não é preciso compreendê-las de forma exata, mas sim, ter uma noção geral do comportamento dos materiais. Segundo eles, as propriedades dos materiais em sua forma quantificada não é o formato adequado de informação, mas sim, de maneira prática, ou seja, como o material pode ser utilizado em relação aos processos de fabricação, quanto peso determinado material suporta, qual é a resistência frente a intempéries, a possibilidade de receber um determinado acabamento, a facilidade de limpeza, e outros. Sendo assim, os seguintes relatos demonstram tal perspectiva.

“(...) eu preciso saber de que maneira o material pode ser usado, se eu posso termo formar, posso colar, então eu vou ter que trabalhar em cima disso." (D14)

"As propriedades em geral, as propriedades mecânicas e geralmente isso está dividido em propriedades mecânicas e propriedades físicas, nas físicas eu tenho a cor, eu tenho alguma outra característica assim mais palpável e a mecânica é de total importância para ver se o material vai suportar o peso que eu vou precisar, se ele vai resistir ao desgaste, tipo de acabamento (...) se ele vai resistir à corrosão.” (D15)

Além das propriedades técnicas, os designers apontam as sensoriais e os aspectos intangíveis como sendo fatores de grande relevância para a seleção de materiais. Em relação às propriedades sensoriais, eles salientam o tato, a visão e a relação destes com a percepção de conforto e a sensação de agradabilidade que um material pode transmitir. Conforme afirma Dias (2009), no processo de interação do usuário com o material, cada órgão dos sentidos é capaz de proporcionar diferentes sensações. A autora explica que a modalidade tátil é um importante sistema na interação usuário-produto nos fatores como o conforto, a satisfação e preferências, pois, cada material, com suas propriedades, induz o usuário a uma percepção que é única e particular. Nas palavras da autora, "a utilização estratégica de materiais é um dos mais influentes meios de que os designers podem valer-se para comunicar e criar conexões emotivas entre os produtos e seus usuários" (p. 2).

No que diz respeito aos aspectos intangíveis dos materiais, os designers realçam as tendências, a moda, a cultura, o simbolismo, os significados, a 
estética. Estes atributos, segundo eles, são importantes para a seleção de materiais pois por meio deles é possível traduzir conceitos, comunicar e projetar de acordo com a cultura. Reis (2003) reforça este entendimento quando propõe que a forma de um produto seja determinada, não apenas pelas propriedades físicas do material, mas também, pelo estilo de representação de uma cultura, no sentido de que os diversos valores semânticos e simbólicos tenham a compreensão adequada dos materiais.

Neste contexto, para os designers, tanto as propriedades técnicas, quanto as sensoriais e os aspectos intangíveis estão interligados na seleção de materiais. Segundo eles, estes atributos se inter-relacionam e são mutuamente interdependentes, ou seja, as propriedades técnicas e sensoriais interferem na estética e vice-versa. Dias (2009) enfatiza que o processo de seleção de materiais é bastante complexo, e além de exigências técnicas, é igualmente importante a tecnologia de produção, economia, sustentabilidade, valores estéticos, propriedades sensoriais e significados culturais e simbólicos. Em perspectiva semelhante, Karana et al. (2007) explicam que os materiais devem cumprir os requisitos funcionais por meio das propriedades técnicas para uso destinado e também recorrer aos sentidos do usuário com suas propriedades sensoriais.

Tal entendimento é expresso nos seguintes depoimentos:

"As questões de acabamento vão influenciar nas questões estéticas, na verdade é um conjunto de propriedades, tanto as questões estéticas quanto as questões mecânicas, ou químicas, ou técnicas. Não adianta ter um produto bonito, um material bonito, uma cadeira bonita e o material não resistir, não ser funcional." (D13)

\begin{abstract}
"A gente trabalha para pessoas, a gente tem que vender o nosso produto e as pessoas primeiramente, elas acabam vendo a estética do produto, o quão belo ele é, o quanto é agradável aos olhos, então é um dos fatores que é importante tanto quanto as outras propriedades, é um conjunto, não adianta." (D13)
\end{abstract}

"Vou para essa parte de buscar, como é o processo que eu posso usar o material de uma forma que ele fique mais interessante esteticamente, se ele permite aplicação de texturas." (D8)

Nesta perspectiva, as características dos materiais estão interligadas, no entanto, segundo os designers, durante o processo de design, a seleção de materiais ocorre de forma gradativa. Para eles, no início do projeto, a seleção 
de materiais concentra-se em uma família de materiais, por exemplo, metais, polímeros, e é focada nas propriedades sensoriais e nos aspectos intangíveis dos materiais, como a estética e o simbolismo, e na fase de projeto detalhado, são levadas em consideração as propriedades técnicas e selecionado o material com maior precisão, como pode ser observado no esquema da figura 4 .

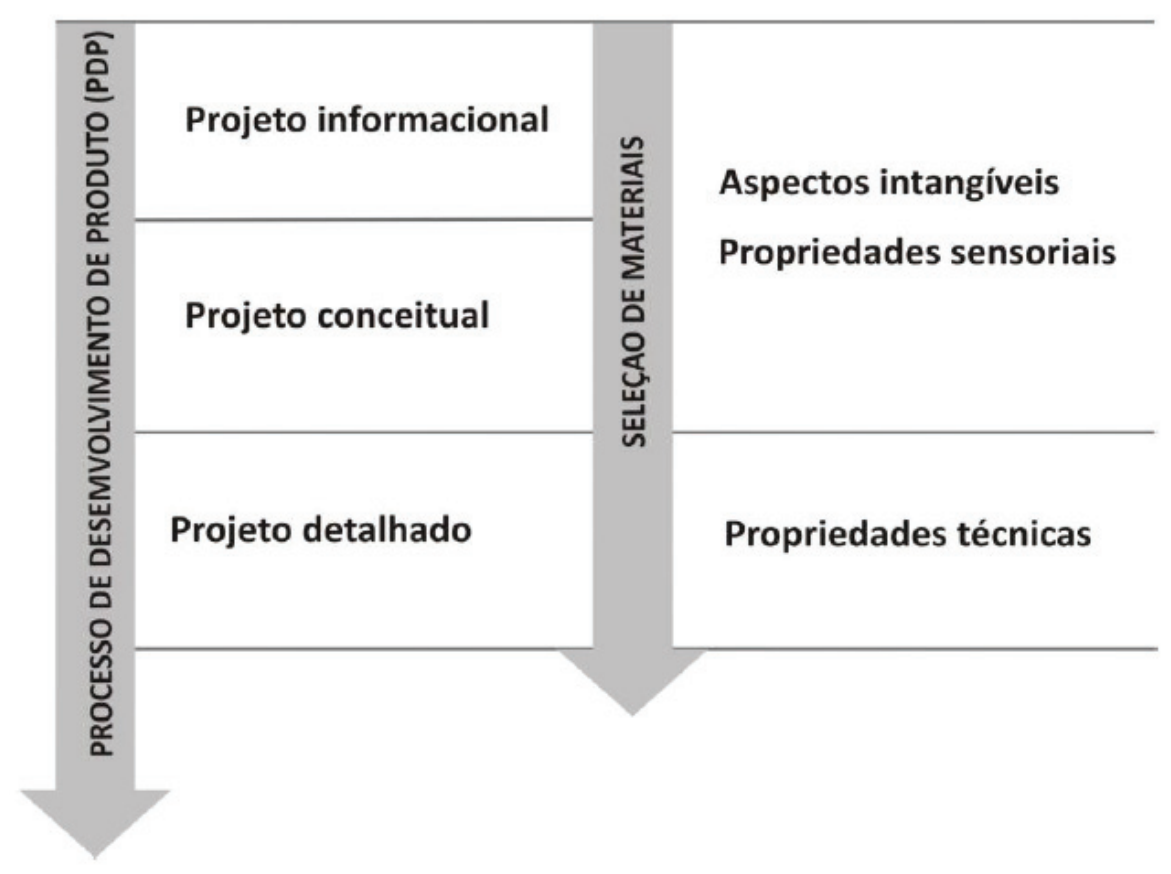

Figura 4. Os aspectos dos materiais relacionados com as fases do PDP na seleção de materiais.

O esquema acima busca relacionar o processo de design com a seleção de materiais. Assim, é possível observar que a seleção de materiais perpassa todas as fases do projeto, sendo que já no início do projeto os designers estão preocupados com a seleção dos materiais. Dessa maneira, na fase informacional e posteriormente na fase de projeto conceitual, segundo os designers, são levadas em consideração as informações dos materiais a respeito de suas propriedades sensoriais e aspectos intangíveis, de forma geral, a estética e o simbolismo. Na sequência do processo de design, os designers afirmaram que buscam informações em torno do comportamento do material em relação às propriedades técnicas. Os depoimentos a seguir expressam esta reflexão: 
“(...) se ele é apropriado para área externa, dependendo do peso da pessoa, depende da resistência. Isso está meio associado, não tão específico, o quanto de peso suporta, vou ver se ele é resistente, e depois eu vou mais afundo, na parte de detalhamento, depois que eu já tenho mais ou menos o material selecionado." (D2)

"No início, pelos menos ter uma ideia de material, não necessariamente o material específico que vai ser utilizado, se for um material polimérico, mais geral." (D13)

"No início eu procuro ver aquela coisa do frio gelado, do toque, se é rugoso, se é agradável, fofinho, isso já no informacional antes de gerar as alternativas." (D2)

Desse modo, tal averiguação vai ao encontro da teoria de Ashby e Johnson (2010) que afirma que a seleção de materiais ocorre na medida em que vão sendo avançadas as etapas do processo de design, assim, os materiais estão presentes no percurso do PDP. Conforme o autor, a seleção de materiais está interligada com o desenvolvimento de produto já na fase inicial, no âmbito do design, a princípio, todos os materiais possuem potencial de uso. No projeto Informacional são elaborados requisitos que possuem objetivos e restrições para atender a proposta do projeto. Estes requisitos, restrições técnicas e de design industrial direcionam a seleção de materiais para a escolha de um número limitado de materiais, o que facilita a análise detalhada dos mesmos para a seleção efetiva.

Neste sentido, os designers apontam que é necessário conhecer o comportamento dos materiais para que o processo da seleção de materiais seja efetivo. Para Lesko (2004) é necessário que os projetistas compreendam os materiais e métodos de fabricação, a fim de criar produtos bem-sucedidos. Ferrante e Walter (2010) afirmam que o conhecimento da área de materiais pode abrir possibilidades para o designer em sua atuação profissional, e ressaltam que é fundamental conhecer as propriedades dos materiais para realizar a escolha apropriada, pois as mais relevantes para determinado produto dependem dos requisitos de projeto e das condições de trabalho. Neste intento, a fim de selecionar os materiais mais apropriados para determinada aplicação, é importante que o designer conheça as opções disponíveis (BEYLERIAN e DENT, (2007). Portanto, entender de materiais é de grande relevância para o processo de design, então, é necessário que o profissional de design tenha uma base sólida de conhecimento sobre eles para que consiga desenvolver produtos eficientes 
e inovadores. Desta forma, a necessidade de compreensão dos materiais por parte dos designers esta de acordo com o entendimento destes autores, pois, é importante conhecer os materiais para determinar as possibilidades de aplicação. Os seguintes depoimentos salientam este entendimento:

"Tem que pensar, conhecer melhor os materiais para ti ter condições de saber se um determinado material pode receber um tratamento térmico especial, pode receber um acabamento especial, então tem como saber se ele custa mais ou menos, se tem como colocar um material com preço mais baixo e aplicar um tratamento nele que vai deixar ele mais bonito esteticamente. "(D15)

"Isso é o básico, tem que conhecer o material para ver o que pode ser feito com ele, quando começamos um projeto a primeira coisa é testar o material, cortar, lixar, colocar fogo, na água, verificar o que é possível fazer, é fundamental.” (D14)

Conforme os entrevistados, a seleção de materiais no processo de design depende da aplicação, das especificações de projeto, do público-alvo, da funcionalidade do produto, entre outros. De acordo com os designers, estes fatores irão nortear a escolha do material para o produto, em que é necessário analisar as características dos materiais como as técnicas, sensoriais, estéticas, simbólicas, para verificar qual material é o mais adequado. Os seguintes depoimentos relatam este entendimento:

"Acho que depende do projeto, se for projetar uma mesa, tem que ser um material resistente, ou dependendo, se for um material que tem que ser mais agradável ao toque, daí depende do projeto, da funcionalidade." (D6)

"Dependendo da aplicação, o foco será mais voltado nas propriedades dos materiais, na resistência, na durabilidade, depende para o que vai ser o projeto e o que o projeto tem que ter para a solução (...) também para que público está sendo desenvolvido esse projeto." (D1)

Neste âmbito, no contexto do design, os materiais podem desempenhar diferentes papéis, eles podem definir o leque de funções de produtos, a durabilidade, os custos, entre outros. Ashby e Johnson (2010) relacionam a 
usabilidade e a ergonomia quando mencionam os seguintes exemplos: objetos pesados podem ficar mais leves com o emprego de ligas de metais leves, polímeros e estruturas de sanduíches preenchidos com espuma, elastômeros podem facilitar a empunhadura e espumas de polímeros permitem superfícies macias ao toque. Sendo assim, os materiais podem auxiliar as soluções de design a cumprirem requisitos propostos no projeto.

\section{Considerações finais}

O presente estudo apresentou uma abordagem que visou contribuir com as discussões sobre os aspectos dos materiais que influenciam a seleção de materiais do ponto de vista de designers de produto. Nos relatos das entrevistas realizadas com designers de produto, emergiram tanto fatores tangíveis quanto intangíveis, aqueles, em forma de propriedades técnicas e estes a partir de percepção sensorial, estética e simbólica. De acordo com os depoimentos, tanto as propriedades técnicas, quanto as sensoriais e os aspectos intangíveis estão interligados na seleção de materiais e são mutuamente interdependentes.

Em relação ao processo de design, nas etapas iniciais, os designers consideram as características intangíveis dos materiais, e nas etapas posteriores, as propriedades técnicas. Segundo eles, a seleção de materiais no processo de design depende da aplicação, das especificações de projeto, do público-alvo, da funcionalidade do produto, entre outros. Para eles, estes aspectos irão guiar a escolha do material para o produto, em que é necessário analisar as características dos materiais como as técnicas, sensoriais, estéticas, simbólicas, para verificar qual material é o mais adequado.

Portanto, a pesquisa reforçou a teoria de que a configuração dos produtos depende dos materiais, de seus aspectos tangíveis, isto é, de suas características físicas determinadas por meio de suas propriedades técnicas, e também dos aspectos intangíveis, como as propriedades sensoriais, os fatores simbólicos, estéticos, que estão diretamente interligados com o contexto cultural.

\section{Referências}

ASHBY, M. F.; JOHNSON, K. Materials and design: the art and science of material selection in product design. Amsterdam: Elsevier/ButterworthHeinemann, 2010. 
DIAS, M. R. A. C. Percepção dos materiais pelos usuários: modelo de avaliação permatus. Tese (Doutorado em Engenharia e Gestão do Conhecimento) Programa de Pós-Graduação em Engenharia e Gestão do Conhecimento, Universidade Federal de Santa Catarina, 2009.

BARDIN, L. Análise de conteúdo. Lisboa: Edições 70, 2011.

BEYLERIAN, G. M.; DENT, A. Ultra materials: how materials innovation is chanching the world. Kingdom: Thame \& Hudson, 2007.

CALLISTER, W. D. Ciência e Engenharia de Materiais: Uma Introdução. São Paulo: LTC, 2006.

FERRANTE, M.; WALTER, Y. A materialização da ideia: noções de materiais para design de produto. Rio de Janeiro: LTC, 2010.

GOMES, F. J. Design do objeto: bases conceituais. São Paulo: Escrituras, 2006.

KARANA, E.; HEKKERT, P.; KANDACHAR, P. Material considerations in product design: a survey on crucial material aspects used by product designers. Materials and Design, 2007.

KINDLEIN J. W.; BUSKO, A. M. P. D. Design e engenharia: como fortalecer a pesquisa e promover o diálogo destas áreas do conhecimento? Actas de Diseño 1. Facultad de Diseño y Comunicación. Universidad de Palermo. Diseño en Palermo. I Encuentro Latinoamericano de Diseño, p. 155-6, 2006.

LESKO, J. Design industrial: materiais e processos de fabricação. São Paulo: Edgard Blücher, 2004.

MANZINI, E. The material of invention. London: The design council, 1989.

REIS, A. A. Matéria, forma e função: a influência material no design industrial. Tese (Doutorado) - Universidade Federal de Santa Catarina, Centro Tecnológico, Programa de Pós-Graduação em Engenharia de Produção, Florianópolis, 2003. 
Recebido em: $11 / 04 / 2014$

Aceito em: 01/06/2014

\section{Como citar}

CALEGARI, Eliana Paula; OLIVEIRA, Branca Freitas de. Aspectos que influenciam a seleção de materiais no processo de design. Arcos Design. Rio de Janeiro: PPD ESDI - UERJ. Volume 8 Número 1 Junho 2014. pp. 1-19. Disponível em: [http://www.epublicacoes.uerj.br/index.php/arcosdesign]

\section{DOI}

http://dx.doi.org/10.12957/arcosdesign.2014.10435

\section{(c) (1) $\$(0)$}

A Revista Arcos Design está licenciada sob uma licença Creative Commons Atribuição - Não Comercial - Compartilha Igual 3.0 Não Adaptada. 